\title{
The Study of the Cultivation Mode of Polytechnic University Students' Guoxue Quality
}

\author{
Lan Wang \\ Kunming University of Science and Technology \\ Kunming, China
}

\begin{abstract}
To strengthen university students' guoxue quality is a research subject responding to the call of the party and country, and also in line with the new current situation needs. For polytechnic universities with relatively weak humanities education, this research subject is more urgent. Cultivation of guoxue quality should begin with three major aspects. First, students should seize the essence of Chinese traditional academic culture connotation through the interpretation of classical texts and reading. Second, students should accept the edification of the traditional Chinese culture through understanding of the traditional Chinese culture and learning. Third, students should cultivate and develop guoxue quality through rich and colorful practical activity.
\end{abstract}

Keywords—university students; guoxue quality; cultivation

\section{INTRODUCTION}

The word "Guoxue" has existed since ancient times, in the book "The rites of the Zhou Dynasty", there is the word "Guoxue", but its meaning is the school set up in the country. In "Modern Chinese Dictionary" published by the commercial press, the interpretation of the word "Guoxue" is: "Guoxue is used to call the traditional academic culture in our country, including philosophy, literature, linguistics, history, archaeology, etc." This is the general definition of guoxue.

\section{THE CURRENT RESEARCH OF UNIVERSITY STUDENTS' GUOXUE QUALITY}

\section{A. The Current Research}

The current research on university students' guoxue quality is not enough.

In the article of "To innovate guoxue practice activity form and improve college students' humane quality" (2012), Xun zong Zhang said "Learning the essence of guoxue is helpful to strengthen the sense of national pride and improve humane quality [1]."

In the article of "Thinking of higher vocational college students' guoxue quality cultivation" (2013), Si ying Liang conducted an investigation of higher vocational college students' guoxue quality, and put forward a proposal that students should read, appreciate and write to improve their guoxue quality and humane quality [2].
In the article of "Statistical analysis of questionnaire on students' guoxue quality and needs" (2014), En rong Xie carried out the sampling in Jiujiang University and said "Now students' existing knowledge level is low, so we need offer appropriate courses to complement the students' knowledge and then improve their guoxue quality [3]."

In the article of "Thinking of integrating guoxue education into college campus cultural construction" (2014), Xia Zhang came up with the essential ways of integrating guoxue education into college campus cultural construction 1. Improve school's emphasis on guoxue education and cognitive; 2 . Integrate guoxue education into college campus cultural construction; 3 . With guoxue course to drive teachers team construction; 4.Enrich the spiritual life of college students [4].

In the article of "Studing of normal school students' guoxue quality and college ancient literature curriculum reform" (2015), Hong lin Gong studied the way of university students' guoxue quality cultivation from the perspective of curriculum reform of ancient literature, and considered that we should integrate the rich resources of guoxue into the regular curriculum teaching and discuss how to excavate the value of guoxue thinking and how to pass on guoxue classic [5].

In the article of "Studing of university students' guoxue quality current situation and the improved method-research on some universities of Hunan province" (2016), Bao bing $\mathrm{Li}$ said "The university students' guoxue quality current situation is not good, there is the general phenomenon of having but a hazy understanding, ability not strong and lacking of learning motivation. The reason is that school teachers and students do not pay enough attention to guoxue education, influenced by instrumental rationality, fast-food culture and western values. For strengthening guoxue education and improving university students' guoxue quality, we should put in a lot of effort on defining the purport of guoxue education, consolidating the basis of learning classical Chinese, offering guoxue courses and editing guoxue textbook carefully[6].',

In the article of "Teacher professional undergraduate students' guoxue quality current situation and puzzle and expectation-research on some normal schools of Hunan province" (2016), Jia Li thought that for improving students' guoxue quality, we should set up the correct view of guoxue, 
perfect the curriculum construction, enhance the correlation of guoxue and life, and broaden the students' learning channels [7].

The current research on polytechnic university students' guoxue quality is not enough.

There are some articles such as "Research on polytechnic university students' guoxue education" (Yan feng Li, 2011), "Research on how to strengthen polytechnic university students' guoxue quality" (Shen ying Xiong, 2011), "The current situation and countermeasure of polytechnic university students' guoxue quality" (Qi tao Su, 2012), "The way of cultivation of polytechnic university students' humane quality in the perspective of the Belt and Road" (Yao Juan Zhang, 2015), "The significance and research of polytechnic university students' guoxue education" (Jian qun $\mathrm{Li}, 2016$ ), and so on. These researchers analyzed the current situation of polytechnic university students' guoxue quality, pointed out the weakness of students' guoxue quality, and explored how to improve the present situation, and then they suggested that we should optimize course arrangement, erect teaching system, build campus culture and cultivate guoxue atmosphere.

\section{B. Conclusion}

In conclusion, of university students' guoxue quality, there are not so many theories that there is not yet a unified view in education circles. The angle of the research is relatively narrow. The researchers mostly stay in the aspect of theory, and cannot put forward the operational stronger practice mode. Especially on how to use modern education technology such as network teaching platform to research on university students' guoxue quality cultivation pattern, there is no special study. So we are needed to study in this aspect.

\section{THE IMPORTANCE OF POLYTECHNIC UNIVERSITY STUdENTS' GuOXue QuALITY Cultivation}

In today's university education system in China, it is an important issue to cultivate university students' guoxue quality. "The decision of the Central Committee of the Communist Party of China and the State Council on deepening educative reform and comprehensively promoting quality education" (13, June, 1999) clearly pointed out: "Higher education should pay attention to innovation ability, practical ability and enterprising spirit of university students, and improve the quality of the college of humanities and science." Guoxue quality is just an important content of humanistic quality.

Since the 1990s, China started the "Chinese hot", many scholars put forward their own views on how to rejuvenate guoxue and advocate guoxue education. One of the most representative scholars is $\mathrm{Mr}$. Bao cheng $\mathrm{Ji}$, the president of Renmin University of China. In 2005, Renmin University of China established the first Chinese Classics Institute in new China, lifted up high the flag of guoxue in the country. For ten years Chinese Classics Institute of Renmin University of China has been adhered to the idea of generalized guoxue, the new concept of guoxue, explored preliminary, and formed a distinctive guoxue education innovation mechanism. In the article of "Leave a place for the institutionalization of guoxue education and research Speaking at the 28th meeting of the Academic Degrees Committee of the State Council" (2011), Mr. Bao cheng Ji thought that according to conventional parlance generalized guoxue refer to the inherent academic in China, ...... guoxue is the source of established country, ...... it reflects the study of soul of China. The study of the soul of China does not need to be limited within a discipline. All scholars who engaged in the study of traditional culture including literature, history and philosophy are under the name of guoxue, as long as they understand tradition with sympathy and have the attitude of developing and expanding guoxue [8].

In the article of "Research on how to strengthen polytechnic university students' guoxue quality" (2011), Shen ying Xiong said "Guoxue quality is steady, basic and adaptive knowledge, ability and emotional attitude which people show in guoxue, in general, it is the ability of knowing, understanding and applying guoxue. For polytechnic university students, guoxue quality cannot only enhance their humanistic spirit, but also inherit Chinese traditional culture and enhance their sense of national identity. But, in fact, polytechnic university students' guoxue quality is not good. So, how to explore a path of strengthening polytechnic university students' guoxue quality is worthy of our in-depth study [9]."

In the report to the 18th National Congress of the Communist Party of China, it is obviously pointed out that we should enhance the overall strength and competitiveness of culture which is the principal symbol of country prosperity and strength and national rejuvenation. In the national conference on publicity and ideological work, Xi jinping emphasized that Chinese excellent traditional culture is the outstanding advantages of the Chinese nation and is our most profound cultural soft power. Guoxue is exactly one of the main content of Chinese excellent traditional culture, and is also an important content of humanistic quality cultivation to university students. Therefore, to strengthen university students' guoxue quality is a research subject responding to the call of the party and country, and also in line with the new current situation needs. For polytechnic universities with relatively weak humanities education, this research subject is more importunate.

\section{THE PATTERN OF POLYTECHNIC UNIVERSITY STudENTS' GuOXue QuALITy Cultivation}

For example, in Kunming University of Science and Technology, we carried out practice of polytechnic university students' guoxue quality cultivation pattern, with the help of our university education online teaching platform, based on the courses of "Ancient Chinese", "Chinese Graphology", "Appreciation of Ancient Chinese Poems and Lyrics", "Ancient Chinese Literature", "Introduction to Classical Chinese", "Introduction to Chinese Culture", "Chinese Calligraphy Training", and "Chinese Culture Skills".

Cultivation of guoxue quality should begin with three major aspects. And yet the pattern of polytechnic university 
students' guoxue quality cultivation is made up of these three aspects.

\section{A. The First Aspect}

First, students should seize the essence of Chinese traditional academic culture connotation through the interpretation of classical texts and reading. Chinese classics are the main part of the guoxue knowledge system. Nevertheless, it is difficult for polytechnic university students to read and understand Chinese classics correctly. We need to guide students to understand cultural classics of the interesting artistic way. Let students are involved in a traditional classics reading activities, have the benefit of the influence of the classical art, in the aesthetic world of music, dance, poetry reading. These activities can be linked to courses such as "Ancient Chinese" "Appreciation of Ancient Chinese Poems and Lyrics" "Ancient Chinese Literature" "Introduction to Classical Chinese". Teachers guide students to realize the interpretation and reading training of classical text including "the work of Hundred Schools of Thought" "Zuo Zhuan" "Strategies of the Warring States" "Guo Yu" "Classical Chinese" "Classical Poems and Lyrics". Thus students can understand and seize the essence of Chinese traditional academic culture connotation. This is the first step on the most basic of guoxue quality cultivation, namely "know".

\section{B. The Second Aspect}

Second, students should accept the edification of the traditional Chinese culture through understanding of the traditional Chinese culture and learning. Guoxue includes spiritual content, also including calligraphy, painting, Beijing Opera, martial arts skills which must rely on repeated training constantly strengthened. These activities can be linked to courses such as "Chinese Graphology" "Introduction to Chinese Culture" "Chinese Calligraphy Training" "Chinese Culture Skills". Teachers guide students to understand and study the Chinese traditional culture, such as understanding the knowledge of cultural inheritance carrier of "Chinese character", practicing Chinese calligraphy, paper cutting, Chinese knot, and tea art skills of Chinese culture. This is the second step on the basis of guoxue quality cultivation, namely "act".

\section{The Third Aspect}

Third, students should cultivate and develop guoxue quality through rich and colorful practical activity. It can make the best use of contemporary abundant network resources and network teaching platform in order to improve. We can collect the Internet a lot of information about the Chinese traditional academic culture, such as music, video, film, news, web pages, books and other online resources, to broaden students' horizons. Through the network teaching platform, we can improve interaction between teachers and students, and encourage students to autonomous learning. We can organize lectures, group discussion, practice, study of the culture and campus salon activities, form guoxue atmosphere on campus, and make students formed in the practice of cultivating guoxue quality. This is the third step on the basis of guoxue quality cultivation, namely "practice".

\section{CONCLUSION}

These three aspects "know" "act" "practice" proceed from the exterior to the interior, from theory to practice, contains "know-act-practice" logical order, in accordance with students' cognitive law of development. This pattern of guoxue quality cultivation may achieve practical results.

We must pay special attention to several problems. First, for polytechnic university students whose humanities and social science foundation are weak, it is difficult to understand and read classical texts. Teachers should neatly take various methods to surmount the difficulties. Second, influenced by the traditional thought of the overemphasis on science and neglect of arts, it is difficult to create a guoxue atmosphere in polytechnic university. We should take the popular form to implement activities according to the students' interests, aiming to extend the range of the target audience, and deeper influence.

\section{REFERENCES}

[1] Xun zong Zhang, "To innovate guoxue practice activity form and improve college students' humane quality”, Language Planning, vol. 12,2012 .

[2] Si ying Liang, "Thinking of higher vocational colleges students' guoxue quality cultivation", journal of Yanan vocational and technical college, vol. 4,2013.

[3] En rong Xie, "Statistical analysis of a questionnaire on students' guoxue quality and needs", Campus English, vol. 28,2014.

[4] Xia Zhang, "Thinking of integrating guoxue education into college campus cultural construction", Higher Education Forum, vol. 12,2014.

[5] Hong lin Gong, "Studing of normal school students' guoxue quality and college ancient literature curriculum reform", China University Teaching, vol. 5,2015.

[6] Bao bing Li, "Studing of university students' guoxue quality current situation and the improved method - research on some universities of Hunan province", China Agricultural Education, vol. 3,2016.

[7] Jia Li, “Teacher professional undergraduate students' guoxue quality current situation and puzzle and expectation - research on some normal schools of Hunan province", Quality Education in Western, vol. 12,2016

[8] Bao cheng Ji, "Leave a place for the institutionalization of guoxue education and research - Speaking at the 28th meeting of the Academic Degrees Committee of the State Council”, China Higher Education Research, vol. 7,2011.

[9] Shen ying Xiong, "Research on how to strengthen polytechnic university students' guoxue quality", Journal of Gannan Medical College, vol. 5,2011. 